\title{
NUMERICAL INVESTIGATION OF NATURAL CONVECTION HEAT TRANSFER FROM HORIZONTAL CIRCULAR CYLINDER IN A VENTED ENCLOSURE FILLED WITH NANOFLUIDS
}

\author{
Omar Mohammad Ali ${ }^{*}$ and Ban Awni Matloob ${ }^{* *}$ \\ *Dept. of Refrigeration and Air Conditioning, Collage of Engineering,Technical Institute of Zakho, Kurdistan -Iraq. \\ *** Dept. of Mechanical, Collage of Engineering, Thermal and Power System, University of Mosul-Iraq.
}

(Received: November 29, 2016; Accepted for publication: February 7, 2017)

\begin{abstract}
In this research, the natural convection heat transfer from the horizontal circular cylinder in a vented enclosure filled with nanofluid is investigated numerically. Governing equations settling in the vorticitystream function formulation is inclusive in the numerical work, which transformed into fitted body coordinate system. The study covered the following ranges of Rayleigh number $10^{4} \leq \operatorname{Ra} \leq 10^{6}$, nanofluid volume fraction $0 \leq \varphi \leq 0.2$, enclosure width $1.667 \leq \mathrm{W} / \mathrm{D} \leq 5$, and opening size $0 \leq \mathrm{O} / \mathrm{W} \leq 1$. The effect of Rayleigh number, nanofluid volume fraction, enclosure width, and opening size on the Nusselt number, flow patterns and isotherms were investigated.

The result shows that the Nusselt number is proportional with Rayleigh number, opening size and volume fraction of nanofluid and inversely proportional with enclosure width. The isotherms and flow patterns display the temperature and flow behaviors with changing studied variables. The thickness of thermal boundary layer decreases with increasing Rayleigh number for each opening size, enclosure width and nanofluid volume fraction.
\end{abstract}

KEY WORDS: Natural Convection, Circular Cylinder, Vented Enclosure, Nanofluid. 
NOMENCLATURE:

\begin{tabular}{|c|c|c|}
\hline code & Definition & $\underline{\text { Unit }}$ \\
\hline $\mathrm{Nu}$ & $\begin{array}{l}\text { The average Nusselt } \\
\text { number, (h.D/k). }\end{array}$ & \\
\hline$d_{i, j}$ & $\begin{array}{l}\text { The expression of } \\
\text { Source in equ. (26). }\end{array}$ & \\
\hline $\mathrm{h}$ & $\begin{array}{l}\text { The coefficient of } \\
\text { Convective heat transfer }\end{array}$ & $\mathrm{W} / \mathrm{m}^{2} \cdot{ }^{\circ} \mathrm{C}$ \\
\hline $\mathrm{Cp}$ & $\begin{array}{l}\text { Specific heat at constant } \\
\text { pressure. }\end{array}$ & $\mathrm{KJ} / \mathrm{kg} \cdot{ }^{\circ} \mathrm{C}$ \\
\hline $\mathrm{J}$ & Jacobian. & \\
\hline $\mathrm{K}_{\mathrm{nf}}$ & $\begin{array}{l}\text { the nanofluid thermal } \\
\text { conductivity . }\end{array}$ & $\mathrm{W} / \mathrm{m} .{ }^{\circ} \mathrm{C}$ \\
\hline $\mathrm{P}$ & $\begin{array}{l}\text { Coordinate control } \\
\text { function. }\end{array}$ & \\
\hline Q & $\begin{array}{l}\text { Coordinate control } \\
\text { function. }\end{array}$ & \\
\hline $\operatorname{Pr}$ & Prandtl number, $(v / \alpha)$. & \\
\hline $\mathrm{Ra}$ & Rayleigh number & \\
\hline g & $\begin{array}{l}\text { Gravitational } \\
\text { acceleration. }\end{array}$ & $\mathrm{m} / \mathrm{s}^{2}$ \\
\hline $\mathrm{t}$ & Time. & seconds \\
\hline $\mathrm{T}$ & Temperature. & ${ }^{\circ} \mathrm{C}$ \\
\hline $\mathrm{u}$ & Velocity in $\mathrm{x}$-direction. & $\mathrm{m} / \mathrm{s}$ \\
\hline $\mathrm{v}$ & Velocity in y-direction. & $\mathrm{m} / \mathrm{s}$ \\
\hline W & Enclosure Width. & $\mathrm{cm}$ \\
\hline$W$ & Relaxation factor. & \\
\hline $\mathrm{x}$ & $\begin{array}{l}\text { Horizontal direction in } \\
\text { physical domain. }\end{array}$ & $\mathrm{m}$ \\
\hline $\mathrm{X}$ & $\begin{array}{l}\text { Dimensionless } \\
\text { horizontal direction in } \\
\text { physical domain. }\end{array}$ & \\
\hline $\mathrm{y}$ & $\begin{array}{l}\text { Vertical direction in } \\
\text { physical domain. }\end{array}$ & $\mathrm{m}$ \\
\hline Y & $\begin{array}{l}\text { Dimensionless vertical } \\
\text { direction in physical } \\
\text { domain. }\end{array}$ & \\
\hline \multicolumn{3}{|c|}{ Greek Symbols } \\
\hline$\Delta \mathrm{T}$ & $\begin{array}{l}\text { Difference between } \\
\text { environmental temperature } \\
\text { \&cylinder surface temp. }\end{array}$ & ${ }^{\circ} \mathrm{C}$ \\
\hline$\varphi$ & Volume fraction. & \\
\hline$\mu_{n f}$ & Nanofluid viscosity. & $\mathrm{kg} / \mathrm{m} . \mathrm{s}$ \\
\hline$\beta$ & $\begin{array}{l}\text { Thermal expansion } \\
\text { Coefficient. }\end{array}$ & $1 /{ }^{\circ} \mathrm{C}$ \\
\hline$\eta$ & $\begin{array}{l}\text { Vertical direction in } \\
\text { computational domain. }\end{array}$ & \\
\hline$\xi$ & $\begin{array}{l}\text { Horizontal direction in } \\
\text { computational domain. }\end{array}$ & \\
\hline$\psi$ & Stream Function. & $1 / \mathrm{sec}$. \\
\hline
\end{tabular}




\begin{tabular}{|c|l|l|}
\hline$\Psi$ & $\begin{array}{l}\text { Dimensionless stream } \\
\text { function. }\end{array}$ & \\
\hline$\omega$ & Vorticity. & $1 / \mathrm{s}$ \\
\hline$\varpi$ & Dimensionless vorticity. & \\
\hline$v$ & Kinematic viscosity. & $\mathrm{m}^{2} / \mathrm{s}$ \\
\hline$\theta$ & $\begin{array}{l}\text { Dimensionless } \\
\text { temperature. }\end{array}$ & \\
\hline$\phi$ & Dependent variable. & $\mathrm{Kg} / \mathrm{m}^{3}$ \\
\hline$\rho_{n f}$ & $\begin{array}{l}\text { The nanofluid effective } \\
\text { density. }\end{array}$ & $\mathrm{m}^{2} / \mathrm{s}$ \\
\hline$\alpha_{n f}$ & $\begin{array}{l}\text { Nanofluid Thermal } \\
\text { diffusivity. }\end{array}$ & \\
\hline Subscript & \\
\hline $\mathrm{S}$ & Cylinder surface. & \\
\hline $\mathrm{nf}$ & Nanofluid. & \\
\hline $\mathrm{e}$ & Enclosure. & \\
\hline $\mathrm{f}$ & Fluid. & \\
\hline $\mathrm{s}$ & Solid. & \\
\hline $\mathrm{X}$ & Derivative in x-direction. & \\
\hline $\mathrm{Y}$ & Derivative in y-direction. & \\
\hline$\xi$ & Derivative in $\xi$-direction. & \\
\hline $\mathrm{D}$ & $\begin{array}{l}\text { Diameter of Circular } \\
\text { cylinder }\end{array}$ & \\
\hline$\Psi$ & Stream function. & \\
\hline $\mathrm{T}$ & Temperature. & \\
\hline$\omega$ & Vorticity & \\
\hline & & \\
\hline
\end{tabular}

\section{INTRODUCTION}

$\mathbf{T}$ There are numerous methods are obtainable to enhance the heat transfer efficiency. One of them is utilizing a fluid substitute the classical fluids like ethylene glycol, water, engine oil and increases the performance of heat transfer called a nanofluid which can be define as a fluid containing particles with nanometer sized and cause an increases in the properties like thermal diffusivity, stability, thermal conductivity, the coefficient of convective heat transfer and viscosity.

Shu \& Zhu [1] studied the natural convection heat transfer in a concentric annulus between a heated inner circular cylinder and a cold outer square cylinder. It is simulated using the differential quadrature (DQ) method. The vorticity stream function formulation is used as the governing equation, and the coordinate transformation technique is introduced in the DQ computation. The transformation coordinate from physical to computational domain is constituted by an analytical term, and all the geometrical parameters can be calculated perfectly. Numerical results for $\mathrm{Ra}$ range from $10^{4}$ to $10^{6}$ and aspect ratios between 1.67 and 5 are presented. It is found that both $\mathrm{Ra}$ and aspect ratio are critical to the patterns of thermal fields and flow. The study suggests that a critical aspect ratio may exist at high Rayleigh number to distinguish the flow and thermal patterns.

Ali et. al. [2] investigated experimentally the natural convection heat transfer from horizontal square cylinder in a square vented enclosure. The studied variables range was $0.25 \leq \mathrm{O} / \mathrm{D} \leq 4$, $10^{7} \leq \mathrm{Ra} \leq 6.6 \times 10^{7}$ and $2 \leq \mathrm{W} / \mathrm{D} \leq 4$. The results showed an Extrusive increase between $\mathrm{Nu}$ and $\mathrm{Ra}$. moreover, $\mathrm{Nu}$ proportionally increases with the vent opening size at low enclosure widths. Supreme enhancement percentage is higher than $20 \%$ for bounded square cylinder, as contrast with unbounded square cylinder.

AbuNada \& Oztab [3] analyzed numerically the effects of inclination angle on fluid flow and natural convection heat transfer in an enclosure 
filled with $\mathrm{Cu}$-nanofluid. Use finite volume technique to resolve the governing equation. Rayleigh number range between $10^{3} \leq \mathrm{Ra} \leq 10^{5}$ and the inclination angle is changed from 0 to 120 . Results presented that, the impact of concentration of the nanoparticles on $\mathrm{Nu}$ is much obvious at low volume fraction than at high volume fraction. Inclination angle considers as a control parameter for a nanofluid filled enclosure. At higher Rayleigh numbers, the percentage enhancement of heat transfer decreases by using nanoparticles.

Present work deals with numerical investigation of natural convection heat transfer, from a horizontal circular cylinder, located in a vented enclosure filled with nanofluid. The flow is laminar. The work discusses the impact of Rayleigh number, nanofluid volume fraction, opening size and enclosure width on flow distributions, temperature distributions and Nusselt number. The study uses various range of volume fraction of nanoparticles, opening size, Rayleigh numbers and enclosure width.

\section{MATHEMATICAL FORMULATION}

The governing equations for incompressible, steady, two dimensional, laminar flow under the Boussinesq approximation are the recognized Navier-stokes equation. Primal variables are used to write the governing equations and then extended to the stream function-vorticity formulation [4]. The properties of thermophysical are shown in table (1) and with a Boussinesq flow supposed to be constant

[5].

Table (1): Thermophysical properties of nanoparticles and fluid, Hakan, et. al.[5].

\begin{tabular}{lll}
\hline Physical Properties & Fluid phase (water) & Nanoparticles $(\mathrm{Cu})$ \\
\hline $\mathrm{Cp}\left(\mathrm{J} / \mathrm{kg} .{ }^{\circ} \mathrm{K}\right)$ & 4197 & 385 \\
\hline $\mathrm{k}\left(\mathrm{W} / \mathrm{m} .{ }^{\circ} \mathrm{K}\right)$ & 0.613 & 400 \\
\hline$\rho\left(\mathrm{kg} / \mathrm{m}^{3}\right)$ & 997.1 & 8933 \\
\hline$\beta \times 10^{-5}\left(\mathrm{~m}^{2} / \mathrm{sec}\right)$ & 21 & 1.67 \\
\hline$\alpha \times 10^{7}\left(\mathrm{~m}^{2} / \mathrm{sec}\right)$ & 1.47 & 1163.1 \\
\hline
\end{tabular}

The governing equation presented as:-

The equation of Continuity:

$\frac{\partial u}{\partial x}+\frac{\partial v}{\partial y}=0$

The equation of $\mathrm{x}$ - momentum:

$\frac{\partial u}{\partial t}+u \frac{\partial u}{\partial x}+v \frac{\partial u}{\partial y}=-\frac{1}{\rho_{n f}} \frac{\partial p}{\partial x}$

$+v_{n f}\left(\frac{\partial^{2} u}{\partial x^{2}}+\frac{\partial^{2} u}{\partial y^{2}}\right)+g \frac{(\rho \dot{\beta})_{n f}}{\rho_{n f}} \Delta T$

The equation of $\mathrm{y}$ - momentum

$\frac{\partial v}{\partial t}+u \frac{\partial v}{\partial x}+v \frac{\partial v}{\partial y}=-\frac{1}{\rho_{n f}} \frac{\partial p}{\partial x}$

$+v_{n f}\left(\frac{\partial^{2} v}{\partial x^{2}}+\frac{\partial^{2} v}{\partial y^{2}}\right)+g \frac{(\rho \dot{\beta})_{n f}}{\rho_{n f}} \Delta T$

The equation of energy 


$$
\begin{aligned}
& \frac{\partial T}{\partial t}+u \frac{\partial T}{\partial x}+v \frac{\partial T}{\partial y}= \\
& \alpha_{n f}\left(\frac{\partial^{2} T}{\partial x^{2}}+\frac{\partial^{2} T}{\partial y^{2}}\right)
\end{aligned}
$$

With Boussinesq approximations, the density is constant for all terms of governing equations, except for the bouncy force term, which density is a linear function of the temperature.

$\rho=\rho_{o}(1-\dot{\beta} \Delta T)$

$\beta$ is the thermal

expansion coefficient [6].

By used stream function-vorticity formulation, the number of the equations can be reduced.

The stream function $(\psi)$ may be offered as

$u=\frac{\partial \psi}{\partial y}, \quad v=-\frac{\partial \psi}{\partial x}$

And the vorticity as

$$
\omega=\frac{\partial v}{\partial x}-\frac{\partial u}{\partial y}
$$

The governing equations in term of the stream function - vorticity formulation become: Continuity Equation

$$
\frac{\partial^{2} \Psi}{\partial \mathrm{X}^{2}}+\frac{\partial^{2} \Psi}{\partial \mathrm{Y}^{2}}=-\varpi
$$

Momentum Equation:

$$
\begin{aligned}
& \frac{\partial \varpi}{\partial t}+\frac{\partial \Psi}{\partial Y} \frac{\partial \varpi}{\partial X}-\frac{\partial \Psi}{\partial X} \frac{\partial \varpi}{\partial Y}= \\
& {\left[\frac{\mathbf{P r}}{(1-\varphi)^{0.25}\left((1-\varphi)+\varphi \frac{\rho_{s}}{\rho_{f}}\right)}\right]} \\
& \left(\frac{\partial^{2} \varpi}{\partial X^{2}}+\frac{\partial^{2} \varpi}{\partial Y^{2}}\right)
\end{aligned}
$$$$
+\operatorname{RaPr}\left[\begin{array}{l}
\frac{1}{\frac{(1-\varphi)}{\varphi} \frac{\rho_{f}}{\rho_{s}}+1} \frac{\beta_{s}}{\beta_{f}}+ \\
\frac{1}{(1-\varphi) \frac{\rho_{f}}{\rho_{s}}+1}
\end{array}\right]
$$

$$
\frac{\partial \boldsymbol{\theta}}{\partial \mathrm{X}}
$$

Energy Equation: 
$\frac{\partial \theta}{\partial t}+\frac{\partial \Psi}{\partial \mathrm{Y}} \frac{\partial \theta}{\partial \mathrm{X}}-\frac{\partial \Psi}{\partial \mathrm{X}} \frac{\partial \theta}{\partial y \mathrm{Y}}=$

$\frac{\partial}{\partial \mathrm{X}}\left(\lambda \frac{\partial \theta}{\partial \mathrm{X}}\right)+\frac{\partial}{\partial \mathrm{Y}}\left(\lambda \frac{\partial \theta}{\partial \mathrm{Y}}\right)$

Where:

$$
\lambda=\frac{\frac{k_{n f}}{k_{f}}}{(1-\varphi)+\varphi \frac{\left(\rho c_{p}\right)_{s}}{\left(\rho c_{p}\right)_{f}}}
$$

The nanofluid thermal diffusivity is [7]:

$$
\alpha_{n f}=\frac{k_{n f}}{\left(\rho c_{p}\right)_{n f}}
$$

The

nanofluid effective density is:

$$
\rho_{n f}=\left((1-\varphi) \rho_{f}+\varphi \rho_{s}\right)
$$

The nanofluid heat capacitance is:

$$
\left(\rho c_{p}\right)_{n f}=\left((1-\varphi)\left(\rho c_{p}\right)_{f}+\varphi\left(\rho c_{p}\right)_{s}\right)
$$

The ratio of nanofluids thermal conductivity is for nanoparticles with spherical shape and approximated by the Maxwell-Garnetts model [8]

$$
\frac{k_{n f}}{k_{f}}=\frac{k_{s}+2 k_{f}-2 \varphi\left(k_{f}-k_{s}\right)}{k_{s}+2 k_{f}+\varphi\left(k_{f}-k_{s}\right)}
$$

The nanofluid

viscosity can be considered as viscosity of a base fluid hold a dilute suspension of tiny rigid spherical particles and it is given by [9].

$\mu_{n f}=\frac{\mu_{f}}{(1-\varphi)^{2.5}}$

The variables are non-dimensionalized by defining the subsequent parameters [10]:
$X=\frac{x}{D}$
$Y=\frac{y}{D}$
$U=\frac{u D}{\alpha_{f}}$
$V=\frac{v D}{\alpha_{f}}$
$\tau=\frac{t \alpha_{f}}{D^{2}}$
$\Psi=\frac{\psi}{\alpha_{f}}$
$\varpi=\frac{\omega D^{2}}{\alpha_{f}}$

$\theta=\frac{\mathrm{T}-\mathrm{T}_{\infty}}{\mathrm{T}_{c}-\mathrm{T}_{\infty}}$

Employing these non-dimensionalized variables, the

governing equations (8)-(10) transformed to this generic shape in the computational space:

$a_{\phi}\left\{\frac{\partial \phi}{\partial t}+\frac{1}{J}\left[\left(\frac{\partial \psi}{\partial \eta} \phi\right)_{\xi}-\left(\frac{\partial \psi}{\partial \xi} \phi\right)_{\eta}\right]\right\}=\nabla\left(b_{\phi} \nabla \phi\right)+d_{\phi}$

Where:

$\frac{\partial \phi}{\partial t}$ is the expression of unsteady.

$\frac{1}{J}\left[\left(\frac{\partial \psi}{\partial \eta} \phi\right)_{\xi}-\left(\frac{\partial \psi}{\partial \xi} \phi\right)_{\eta}\right]$ Is the expression of convective.

$\nabla\left(b_{\phi} \nabla \phi\right)$ Is the expression of diffusion. 
$d_{\phi}$ is the expression of source.

The expression of diffusion in equation (18) is:

$\nabla\left(b_{\phi} \nabla \phi\right)=\frac{1}{J^{2}}\left\{\begin{array}{l}\gamma \frac{\partial}{\partial \xi}\left(b_{\phi} \frac{\partial \phi}{\partial \xi}\right)-\beta \frac{\partial}{\partial \xi}\left(b_{\phi} \frac{\partial \phi}{\partial \eta}\right)- \\ \beta \frac{\partial}{\partial \eta}\left(b_{\phi} \frac{\partial \phi}{\partial \xi}\right)+\alpha \frac{\partial}{\partial \eta}\left(b_{\phi} \frac{\partial \phi}{\partial \eta}\right)\end{array}\right\}$

$+b_{\phi}\left[\sigma \frac{\partial \phi}{\partial \eta}+\tau \frac{\partial \phi}{\partial \xi}\right]$

Where $\sigma=\frac{\partial^{2} \xi}{\partial x^{2}}+\frac{\partial^{2} \xi}{\partial y^{2}}$ and $\tau=\frac{\partial^{2} \eta}{\partial x^{2}}+\frac{\partial^{2} \eta}{\partial y^{2}} \quad$ Changing the dependent variable $\phi$ to get the governing equations as table (2) [11].

\section{GRID GENERATION}

Geometric data of the Cartesian coordinates can be formed using algebraic methods, which is used to produce an initial computational grid points.

The equations of elliptic partial differential that used are Poisson equations:

$$
\xi_{x x}+\xi_{y y}=P(\xi, \eta) \quad \text { (20a) } \eta_{x x}+\eta_{y y}=Q(\xi, \eta)
$$

(20b) Transforming

above equations in computational space yields a set of two elliptical PDEs of the form [12]:

$$
\begin{aligned}
& \alpha x_{\xi \xi}-2 \beta x_{\xi \eta}+\gamma x_{\eta \eta}+ \\
& J^{2}\left(P x_{\xi}+Q x_{\eta}\right)=0 \\
& \alpha y_{\xi \xi}-2 \beta y_{\xi \eta}+\gamma y_{\eta \eta}+ \\
& J^{2}\left(P y_{\xi}+Q y_{\eta}\right)=0
\end{aligned}
$$

Where

$$
\begin{aligned}
& \alpha=x_{\eta}^{2}+y_{\eta}^{2} ; \beta=x_{\xi} x_{\eta}+y_{\xi} y_{\eta} ; \\
& \gamma=x_{\xi}^{2}+y_{\xi}^{2}
\end{aligned}
$$

The coordinate control functions $\mathrm{P}$ and Q could be selected to impact the grid of structure, [13]. The method of Successive over Relaxation (SOR) is used to acquire the solutions of Poisson and Laplace equation. The relaxation factor is equal to 1.4. The transformation of the physical domains into computational domains utilizing elliptic grid generation is illustrated in figure (1) [10].

\section{METHOD OF SOLUTION}

The hybrid difference scheme is a combination of central and upwind difference scheme. It makes use of the central difference scheme, which is second order accurate for small peclet numbers. It turns to upwind difference scheme when central difference scheme produces inaccurate results for high peclet numbers[14].

The general discretization equation becomes:

$$
\begin{aligned}
& a_{P} \phi_{P}=a_{E} \phi_{E}+a_{W} \phi_{W}+a_{N} \phi_{N}+a_{S} \phi_{S} \\
& +a_{P}^{o} \phi_{P}^{o}+a_{M}\left(\begin{array}{l}
\phi_{i+1, j+1}-\phi_{i-1, j-1} \\
-\phi_{i+1, j-1}+\phi_{i-1, j+1}
\end{array}\right)+d_{i, j}
\end{aligned}
$$

Where 


$$
\begin{aligned}
& a_{M}=\frac{\beta b_{\phi}}{2 J^{2}} \\
& a_{P^{o}}=\frac{1}{\Delta t} \\
& a_{P}=a_{E}+a_{W}+a_{N}+a_{S}+a_{P}^{o} \\
& \begin{cases}\omega_{i, j} & \text { for } \psi \text { equation } \\
0 & \text { for temp. equation }\end{cases} \\
& d_{i, j}=\left\{\begin{array}{l}
\operatorname{RaPrff} \\
8 J
\end{array}\left\{\begin{array}{l}
\theta_{i+1, j}\left(\begin{array}{l}
y_{i+1, j+1}-y_{i+1, j-1}+ \\
y_{i, j+1}-y_{i, j-1}
\end{array}\right)+ \\
\theta_{i, j-1}\left(\begin{array}{l}
y_{i+1, j-1}-y_{i-1, j-1}+ \\
y_{i+1, j}-y_{i-1, j}
\end{array}\right)- \\
\theta_{i-1, j}\left(\begin{array}{l}
y_{i-1, j+1}-y_{i-1, j-1}+ \\
y_{i, j+1}-y_{i, j-1}
\end{array}\right) \\
\theta_{i, j+1}\left(\begin{array}{l}
y_{i+1, j+1}-y_{i-1, j+1}+ \\
y_{i+1, j}-y_{i-1, j}
\end{array}\right)
\end{array}\right\}\right.
\end{aligned}
$$

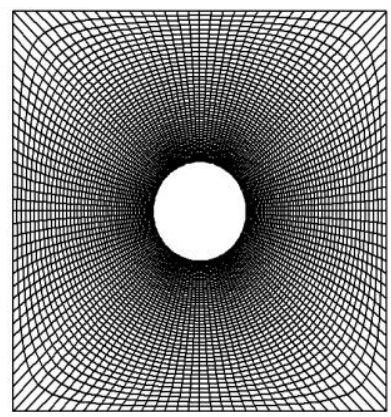

Fig.(1): Transformations of the physical domains into computational domains using elliptic grid generation.

Where $a_{W}, a_{E}, a_{S}, a_{N}, a_{M}, a_{p}^{\circ}$ are coefficients of the discretization equation [10].

Using the method of alternating direction (ADI), the resulting algebraic equation is settled in two sweeps. In the premier sweep, the equations are solved implicitly in $\xi$-direction and explicitly in $\eta$-direction. The implicit discretization equation in $\xi$-direction is solved by using Cyclic TriDiagonal Matrix Algorithm (CTDMA) because of its cyclic boundary conditions. On the other sweep, the equations are solved implicitly in $\eta$ direction and explicit in $\xi$-direction. The implicit discretization equation in $\eta$-direction is solved by using TriDiagonal Matrix Algorithm (TDMA) [6].

The initial conditions of the flux between vented enclosure and heated cylinder are: 
$\left.\begin{array}{l}\psi=0 . \\ \theta=0 . \\ \omega=0 .\end{array}\right\} \quad$ For $\mathrm{t}=0$

At the cylinder surface

assume constant temperature and for the vorticity this equation is applied

$\varpi=\frac{2 \gamma}{J^{2}}\left(\psi_{i, 1}-\psi_{i, 2}\right)$

The enclosure wall is considered as adiabatic surface (no heat transfer)

$\theta=0$

And for

vorticity this equation is applied:

$\varpi=\frac{2 \gamma}{J^{2}}\left(\psi_{i, m}-\psi_{i, m-1}\right)$

At the lower vent, temperature is supposed equal to free stream flow temperature and the flow assumed as uniform so

$\varpi=0$

The local heat transfer along the upper opening was equal to the local heat transfer at just point downstream of it:

$\begin{array}{ll}\left.\frac{\partial \theta}{\partial \eta}\right|_{m}=0 & \text { (32) And for the vorticity }\end{array}$

$\varpi=\frac{2 \gamma}{J^{2}}\left(\psi_{i, m}-\psi_{i, m-1}\right)+\frac{1}{J^{2}}$

$\left(2 \beta \frac{\partial^{2} \psi}{\partial \eta \partial \xi}-\tau \frac{\partial \psi}{\partial \xi}-\frac{\partial \psi}{\partial \xi}(2 \gamma+\sigma)-\alpha \frac{\partial^{2} \psi}{\partial \xi^{2}}\right)$

Employing this equation by used backward finite difference method for first and second derivative.

The stream function for the enclosure is supposed as constant. While for the cylinder, which is a solid surface supposed as zero because nothing enters into it or leaves from it.

For calculation Nusselt number which is used in the determination of heat transfer coefficient entailed the next steps:

$$
N u=\frac{h D}{k_{f}}
$$

The coefficient of heat transfer is:

$h=\frac{q_{w}}{T_{H}-T_{l}}$

The thermal conductivity is:

$k_{n f}=-\frac{q_{w}}{\partial \theta / \partial n}$

The Nusselt number is written as:

$N u=-\frac{k_{n f}}{k_{f}} \int_{0}^{2 \pi} \frac{\partial \theta}{\partial n} \partial \zeta$

The derivative of the non_dimensional temperature is calculated utilizing the next form,[4]:

$\left.\frac{\partial \theta}{\partial n}\right|_{\eta=\text { const. }}=\frac{1}{J \sqrt{\gamma}}\left(-\beta \theta_{\xi}+\gamma \theta_{\eta}\right)=\frac{\sqrt{\gamma}}{J} \frac{\partial \theta}{\partial \eta}$ 
$\theta \xi=0$ at cylinder surface.

The mass flowrate flowing in and out through the lower and the upper opening is due to the density variance; and it is represented as

$\dot{m}=\left.\sum \rho_{i, m} \frac{u_{i, m}+u_{i+1, m}}{2} \Delta x\right|_{\eta=m}$

Where:

$\rho_{i, m}=\rho_{n f}=\left((1-\varphi) \rho_{f}+\varphi \rho_{s}\right)$ at the lower vent and the upper vent.

The numerical algorithm run by a computer program in (Fortran 90), that is generic for a natural convection from heated cylinder located in a vented enclosure.

\section{STABILITY AND GRID INDEPENDENCY TEST}

A stability investigation of the numerical method is made for the state $\mathrm{Ra}=10^{5}, \mathrm{~W} / \mathrm{D}=1.667$, $\mathrm{O} / \mathrm{W}=0.5, \varphi=0.05$ and $\mathrm{Pr}=0.7$. Three time steps are chosen with value $1 \times 10^{-6}, 5 \times 10^{-6}, 5 \times 10^{-7}$. The highest difference between $\mathrm{Nu}$ values with various time steps is $3 \%$.

A wide mesh testing procedure was carried to guarantee a grid independent solution. Different mesh combinations were used for the state of $\mathrm{W} / \mathrm{D}=2.5, \mathrm{Ra}=10^{4}$ and $10^{5}, \mathrm{Pr}=6.2$. For the present simulation, three grid sizes of $96 * 25,128 * 45$ and $192 * 50$ are chosen to test the independency of the results with the grid variation. It is observed that the total number of grid points is 2425,5805 and 9650 respectively. The present code was tested for grid independence by calculating the average Nusselt number. Numerical experiments showed that when the mesh size is above $96^{*} 45$, the computed $\mathrm{Nu}$ remain the same. However for the rest of the calculation in this study choose a grid size of $128 * 45$ for better accuracy.

\section{VALIDATION TEST}

The code validation is an important part for numerical work. A Fortran 90 control volume finite difference method code is used in this paper. The code was validated against the problem of natural convection heat transfer between a heated horizontal cylinder placed concentrically inside a square enclosure by Moukalled \& Acharya [15]. To test the code validation, the natural convection problem for high temperature inner circular cylinder and a low temperature outer vented enclosure was tested. The average Nusselt number and maximum stream function for the test case and the work of Moukalled and Acharya are compared in table (3), for prandtl number $\operatorname{Pr}=0.7$, different values of the enclosure width
W/D $=1.667,2.5$ and 5 with Rayleigh number $\mathrm{Ra}=10^{4}$ and $10^{5}$, opening size $\mathrm{O} / \mathrm{W}=0$ and volume fraction of nanofluid $\varphi=0$. From table (3) it is clear that the present results are in good agreement with those of Moukalled and Acharya.

\section{RESULTS AND DISCUSSION}

The numerical result are given for $\mathrm{Ra}=10^{4} 10^{5}$ and $10^{6}$ and nanoparticles volume fraction for copper $(\mathrm{Cu})$ based nanofluids which are $\varphi=0$, $0.05,0.1,0.15,0.2$. Water is the base fluid which means the prandtl number equal 6.2. The enclosure width $\mathrm{W} / \mathrm{D}=1.667,2.5$ and 5 and opening size $\mathrm{O} / \mathrm{W}=0,0.2,0.5,0.8,1$. The results obtained are investigated under various combinations of relevant parameters involved in the study.

\section{FLOW PATTERNS AND ISOTHERMS}

Figure (2) display the influence of the nanoparticles volume fraction $\varphi=0,0.05,0.1,0.15$ and 0.2 on the streamline at different Rayleigh numbers $\mathrm{Ra}=10^{4}, 10^{5}$ and $10^{6}$ and opening size $\mathrm{O} / \mathrm{W}=0.5$ for enclosure width $\mathrm{W} / \mathrm{D}=1.667$. At $\mathrm{Ra}=10^{4}$, the maximum stream function value varies proportionally with volume fraction of nanofluid. Two identical eddies clarify on two sides of the enclosure wall. Eddies growth linearly below the heat source for all nanoparticles volume faction. The flow is uniformed about the vertical line through the center of the circular cylinder. At pure fluid $\varphi=0$, the flow is weak, the maximum value of stream function $\psi_{\max }=0.3435332$. The densely packed of the flow pattern is small. An increase in volume fraction of nanofluid, the maximum stream

function value increases slightly with small value. At volume fraction of nanofluid $\varphi=0.1$, $\psi_{\max }=0.6175973$. The densely packed of the flow pattern increase. At $\varphi=0.2$, the flow is stronger. The value of maximum stream function becomes $\psi_{\max }=0.8591641$. 
However, for $\mathrm{Ra}=10^{5}$, the strength of the flow increases and the maximum stream function value enhances. Eddies shape is not uniform. The flow is symmetrical about the vertical line of the circular cylinder. The maximum stream function value change between $\psi_{\max }=4.981700$ at $\varphi=0$ to $\psi_{\max }=13.456240$ at $\varphi=0.2$. As it can be seen at nanoparticles volume fraction $\varphi=0$ the densely packed of the flow pattern is small. Maximum stream function value increases with increasing the volume fraction of nanofluid. At $\varphi=0.05$ the maximum stream function value $\psi_{\max }=7.196921$. The densely packed of the flow pattern is high. Four small eddies appear in two sides. At $\varphi=0.2$ the flow is stronger. The densely packed of flow is high. Two eddies appear on the sides of enclosure wall, one longitudinal and one small.

At high Rayleigh number $\mathrm{Ra}=10^{6}$, for all volume fraction of nanofluid, the densely packed of the flow is high. The streamlines move up along the inner heat source. The flow is strong and two small eddies appear on both sides of the enclosure wall. The streamlines are closer to cylinder wall. The value of maximum stream function increases with remarkable value by increasing the nanoparticles volume fraction. The maximum value of stream function varies between $\psi_{\max }=38.470870$ at $\varphi=0$ and $\psi_{\max }=79.035880$ at $\varphi=0.2$.

Figure (3) study the impact of the nanoparticles volume fraction $\varphi=0,0.05,0.1,0.15$ and 0.2 on the isotherms at various Rayleigh numbers $\mathrm{Ra}=10^{4}, 10^{5}$ and $10^{6}$ and opening size $\mathrm{O} / \mathrm{W}=0.5$ for enclosure width $\mathrm{W} / \mathrm{D}=1.667$. At $\mathrm{Ra}=10^{4}$,

heat transfer is fundamentally dominated by conduction with little effect of convection heat transfer. The isotherm not influenced with increasing the volume fraction of nanofliud. The isotherm is symmetrical about the vertical line through the center of the circular cylinder. The isotherms displayed as rings around the heat source. The thickness of thermal boundary layer is large. The flow velocity is too small to effect the temperature distribution. The temperature distribution is uniform due to quasi-conduction heat transfer regime where formed clearly.

As Rayleigh number increase to $\mathrm{Ra}=10^{5}$, the isotherm not effected by increasing the volume fraction. A thermal plume region appears above the cylinder. The heat transfer is mainly dominated by convection. The thermal boundary layer becomes thinner. The shape of isotherm has little distortion under the heat source. The isotherm has one main thermal plume that appears above the cylinder.

At high Rayleigh number $\mathrm{Ra}=10^{6}$, the isotherm pattern change significantly as an indication that convection is the dominate mechanism for heat transfer. The temperature distribution is similar and independent on nanoparticles volume fraction. The isotherm becomes random and non uniform. The core of the plume moves toward the top of inner cylinder. The thermal boundary layer is very thin.

The effect of various opening size $\mathrm{O} / \mathrm{W}=0,0.2$, $0.5,0.8,1$, on the streamline at $\mathrm{W} / \mathrm{D}=2.5, \mathrm{Ra}=10^{5}$ and $\varphi=0,0.05,0.1,0.15,0.2$ are presented in Figure (4). For $\mathrm{O} / \mathrm{W}=5$, it can be notice that for all values of the nanofluid volume fraction, the streamlines extended from the lower opening to the upper opening. Secondary short and asymmetrical eddies appear at the upper sides of the enclosure, that the flow region area becomes small. The strength of streamline and the densely packed of the flow pattern increase with increasing the nanofluid volume fraction until $\varphi=0.1$, then decrease more and more until $\varphi=0.2$. The maximum value of stream function increases proportionally with increase the volume fraction of nanoparticles. Maximum stream function value varies between $\psi_{\max }=13.028840$ at volume fraction $\varphi=0$ to $\psi_{\max }=28.293100$ at $\varphi=0.2$.

Figure (5) illustrate the impact of various opening size $\mathrm{O} / \mathrm{W}=0,0.2,0.5,0.8,1$ on the isotherm at $\mathrm{W} / \mathrm{D}=2.5, \mathrm{Ra}=10^{5}$ and $\varphi=0,0.05,0.1$, $0.15,0.2$. It is obvious that at $\mathrm{Ra}=10^{5}$, the convection heat transfer is the dominant mode. A thermal plume appears on the top of the heat source. The thermal boundary layer becomes thinner. For all opening size, the isotherms are similar and independent of the volume fraction of nanofluid. The isotherm is symmetrical about the vertical axis through the center of the circular cylinder It can be observed for $\mathrm{O} / \mathrm{W}=0.5,0.8$ and 1 , the isotherms patterns change significantly. A thermal plume impinges on the top of the circular cylinder. The core of the plume moves toward the top of the inner cylinder and approaches the vertical centerline of the cylinder.

Figure (6) investigates the effect of enclosure width $\mathrm{W} / \mathrm{D}=1.667$ on the streamline at $\mathrm{Ra}=10^{5}$, $\mathrm{O} / \mathrm{W}=0.5$ and $\varphi=0,0.05,0.1,0.15,0.2$. For all volume fractions of nanofluid, the flow moves up from the lower vent to the upper vent along the 
inner heated circular cylinder. The flow pattern is not symmetrical on both sides of the heat source. Maximum stream function value varies between $\psi_{\max }=4.981700$ at $\varphi=0$ and $\psi_{\max }=13.456240$ at $\varphi=0.2$. Small area of flow region means the stagnant area is large. As the volume fraction of the nanofluid increases, the flow strength enhancement and the maximum stream function increases. At volume fraction $\varphi=0$, the flow strength is relatively weak, therefore; the maximum stream function has small value. The densely packed of the flow pattern is small. The enclosure has two plumes; one of them is small and the other extended in the longitudinal axis below the heat source. At the case of nanofluid volume fraction $\varphi=0.05$, four small eddies appear on both side of enclosure wall. The densely packed of the flow pattern increases. The flow strength increases, therefore; the maximum stream function enhances to $\psi_{\max }=7.196921$. For $\varphi=0.1$, two small eddies appear at the left and one longitudinal eddy at the right side of the enclosure wall. The densely packed of the flow decrease. The flow strength increases and the maximum stream function value is $\psi_{\max }=9.377060$. The flow region area is small and the stagnant area is large. At $\varphi=0.15$ and 0.2 , the flow is strong and the maximum stream function value increase to high value. Two different sizes of the eddies appear on both sides of the enclosure wall.

Figure (7) presented the influence of enclosure width $\mathrm{W} / \mathrm{D}=1.667$ on the isotherm at $\mathrm{Ra}=10^{5}$, $\mathrm{O} / \mathrm{W}=0.5$ and $\varphi=0,0.05,0.1,0.15,0.2$. It is obvious that the isotherm not effected by increasing the volume fraction of nanofluid. A wide thermal plume is clear above the heat source. The distortion near the enclosure wall is high. The thermal boundary layer is thin because the heat transfer is mainly dominated by convection.

\section{Overall heat transfer coefficient}

Nusselt number is a substantial non dimensional parameter in convective heat transfer. Figure (8) display the variation of $\mathrm{Nu}$ with the opening size for $\mathrm{W} / \mathrm{D}=1.667$ with different Rayleigh numbers. At $\mathrm{Ra}=10^{4}$, figure $8(\mathrm{a})$, the average $\mathrm{Nu}$ is approximately constant with the variation of the opening size for each nanofluid volume fraction, while; the average $\mathrm{Nu}$ increase with increasing the volume fraction of nanofluid for each opening size. The maximum increase in the $\mathrm{Nu}$ occurs at volume fraction $\varphi=0$ with a percentage value $2.634 \%$.

At $\mathrm{Ra}=10^{5}$, as shown in figure $8(\mathrm{~b})$, the average $\mathrm{Nu}$ increase with increasing the nanofluid volume fraction for each opening size. The average $\mathrm{Nu}$ is approximately constant for $\mathrm{O} / \mathrm{W} \leq 0.2$ for each nanofluid volume fraction. The $\mathrm{Nu}$ enhances linearly with increasing the opening size for the range $0.2<\mathrm{O} / \mathrm{W} \leq 1$. The maximum enhancement for average $\mathrm{Nu}$ can be seen at volume fraction $\varphi=0.15$ with a percentage value $38.65 \%$.

At $\mathrm{Ra}=10^{6}$, as shown in figure $8(\mathrm{c})$, the same behavior occur between the average $\mathrm{Nu}$ and nanofluid volume fraction as those for $\mathrm{Ra}=10^{4}$ and $10^{5}$ for each opening size. The average $\mathrm{Nu}$ increases with increasing the opening size at each nanofluid volume fraction for $\mathrm{O} / \mathrm{W} \leq 0.5$. The average $\mathrm{Nu}$ enhancement is very small at each nanofluid volume fraction for $\mathrm{O} / \mathrm{W}>0.5$. The maximum increase in the average $\mathrm{Nu}$ exist at volume fraction $\varphi=0.15$ with a percentage value $43.14 \%$. It is observable the maximum enhancement in average $\mathrm{Nu}$ occurs for high values of nanofluid volume fraction. 


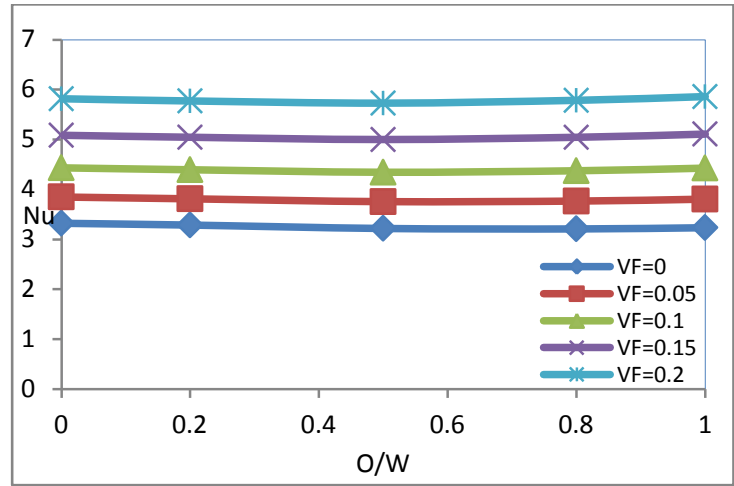

(a)

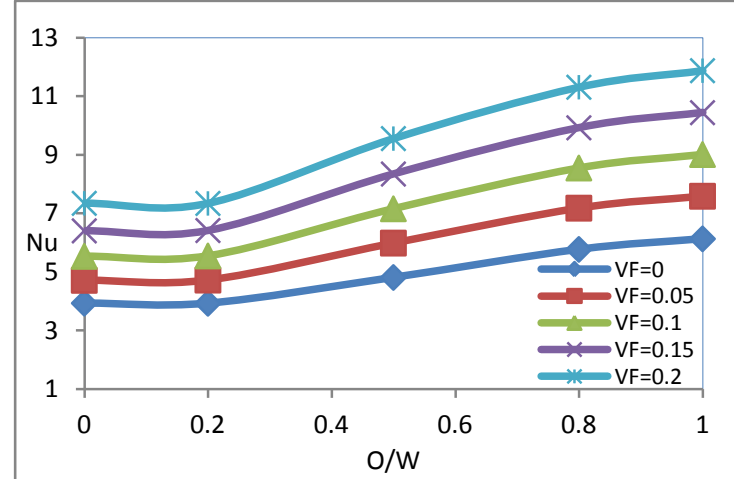

(b)

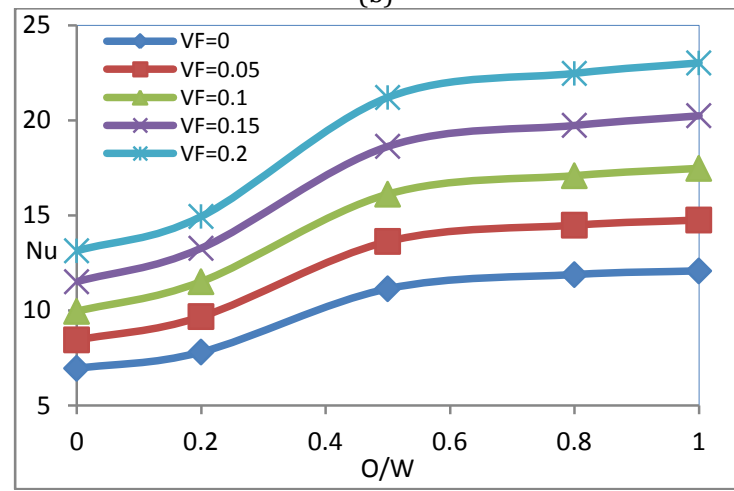

(c)

Fig.(8): Effect of opening size on Nusselt number for each volume fraction, (a) $\mathrm{Ra}=10^{4}$, (b) $\mathrm{Ra}=10^{5}$, (c) $\mathrm{Ra}=10^{6}$ and enclosure width $\mathrm{W} / \mathrm{D}=1.667$.

Figure (9) illustrate the influence of the Rayleigh number on the average Nusselt number for enclosure width $\mathrm{W} / \mathrm{D}=1.667$. At volume fraction $\varphi=0$, figure $9(\mathrm{a})$, the average $\mathrm{Nu}$ varies proportionally with the opening size for each Rayleigh number. The average Nu increases with increasing Rayleigh number for each opening size because an increase in Rayleigh number cause increase in the buoyancy force which accelerates the flow motion and led to an enhancement in the $\mathrm{Nu}$. For Rayleigh number range $10^{4} \leq \mathrm{Ra} \leq 10^{5}$, the average $\mathrm{Nu}$ increases with small value for each opening size. The enhancement in average $\mathrm{Nu}$ with high value is recorded for Rayleigh number range $10^{5}<\mathrm{Ra} \leq 10^{6}$.

Figure $9(b, c)$ shows the case of $\varphi=0.05$ and 0.1 respectively, which is similar to the case of $\varphi=0$ that those have the same relation between the opening size and average $\mathrm{Nu}$ at each Rayleigh number. The average $\mathrm{Nu}$ increases with increasing Rayleigh number for each opening size. In the case of Rayleigh number range $10^{4} \leq \mathrm{Ra} \leq 10^{5}$, the average $\mathrm{Nu}$ increases slightly for each opening size. The enhancement in $\mathrm{Nu}$ is more pronounced with the range $10^{5}<\mathrm{Ra} \leq 10^{6}$.

For nanofluid volume fraction $\varphi=0.15$ and 0.2 , as presented in figure $9(\mathrm{~d}, \mathrm{e})$, the average $\mathrm{Nu}$ 
varies proportionally with the Rayleigh number for each opening size. Average $\mathrm{Nu}$ increases with small value for Rayleigh number range $10^{4} \leq \mathrm{Ra} \leq 10^{5}$ for each opening size. On the other hand, there is a considerable enhancement in average $\mathrm{Nu}$ with Rayleigh number range $10^{5}<\mathrm{Ra} \leq 10^{6}$.

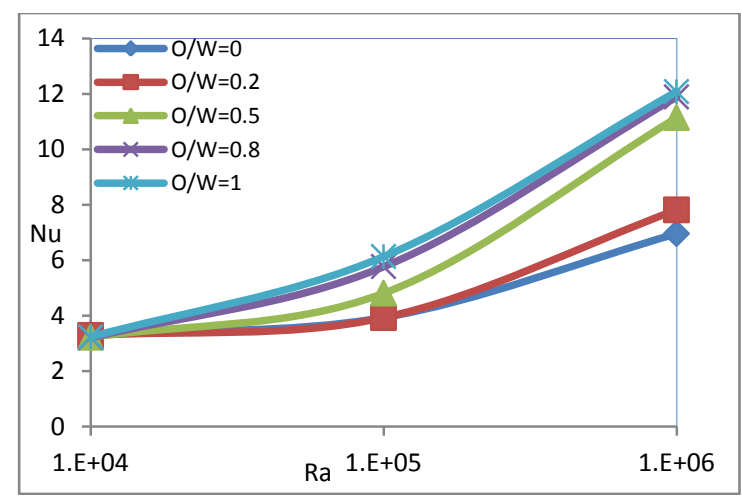

(a)

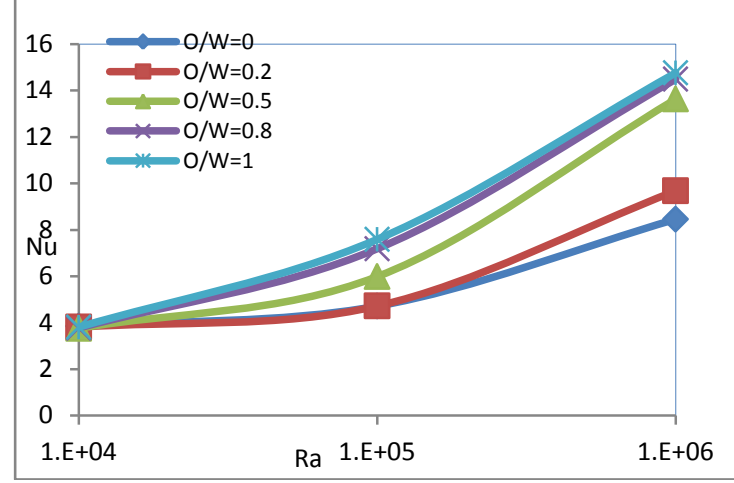

(b)

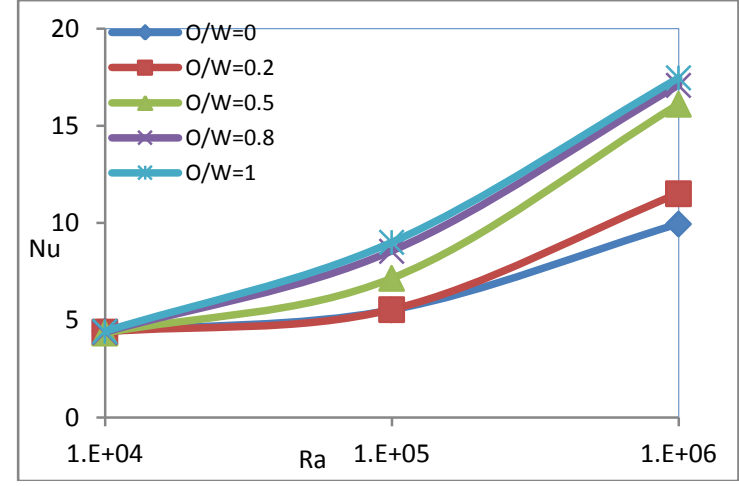

(c) 


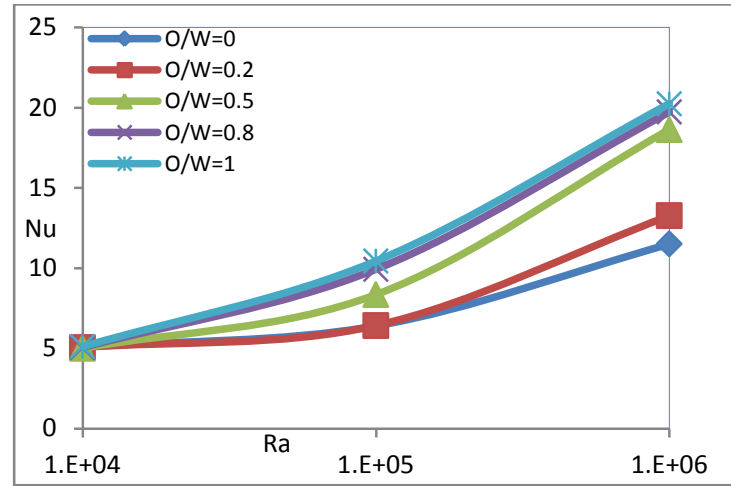

(d)

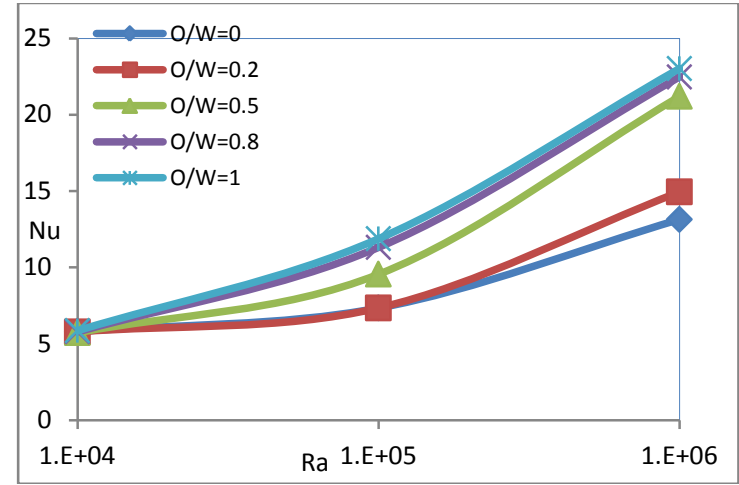

(e)

Fig. (9): Effect of Rayleigh number on Nusselt number for each opening size, (a) $\varphi=0$, (b) $\varphi=0.05$, (c) $\varphi=0.1$, (d) $\varphi=0.15$, (e) $\varphi=0.2$ and enclosure width $\mathrm{W} / \mathrm{D}=1.667$.

Figure (10) studies the effect of enclosure width on Nusselt number for opening size $\mathrm{O} / \mathrm{W}=0.5$ with different Rayleigh numbers. The case of $\mathrm{Ra}=10^{4}$, Figure 10 (a). With the addition of the nanoparticles volume fraction causes an increase in average $\mathrm{Nu}$ value for each enclosure width. As the enclosure width decrease the value of the average $\mathrm{Nu}$ increase for each volume fraction of nanoparticles. For enclosure width range $1.667 \leq \mathrm{W} / \mathrm{D} \leq 2.5$, the average $\mathrm{Nu}$ decrease with small value for each nanoparticles volume fraction. The variation in average $\mathrm{Nu}$ is approximately constant at the enclosure width range $2.5<\mathrm{W} / \mathrm{D} \leq 5$.

For $\mathrm{Ra}=10^{5}$ that presented in Figure 10(b), the average $\mathrm{Nu}$ varies proportionally with the nanoparticles volume fraction for each enclosure width. The Nusselt number decreasing is almost constant with the variation of the enclosure width at $1.667 \leq \mathrm{W} / \mathrm{D} \leq 2.5$ for each nanoparticles volume fraction. The average $\mathrm{Nu}$ decreases slightly for enclosure width range $2.5<\mathrm{W} / \mathrm{D} \leq 5$.

At high Rayleigh number $\mathrm{Ra}=10^{6}$ figure $10(\mathrm{c})$, show significant decrease in average $\mathrm{Nu}$ for enclosure width range $1.667 \leq \mathrm{W} / \mathrm{D} \leq 2.5$ for each nanopartice volume fraction. The decrease in average $\mathrm{Nu}$ value is more noticeable by using enclosure width range $2.5<\mathrm{W} / \mathrm{D} \leq 5$. The addition of nanoparticle volume fraction increases the value of the Nusselt number for each enclosure width. 


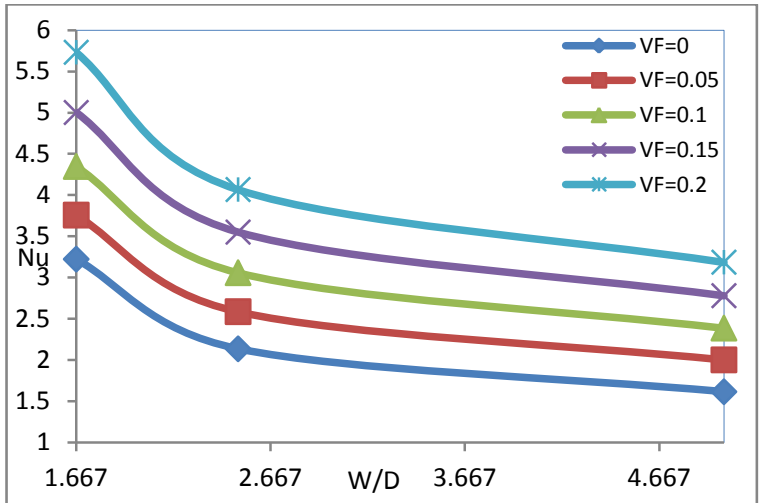

(a)

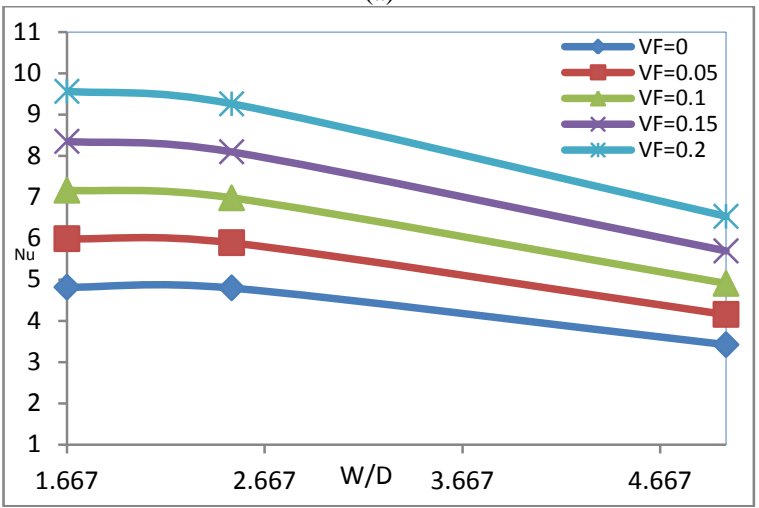

(b)

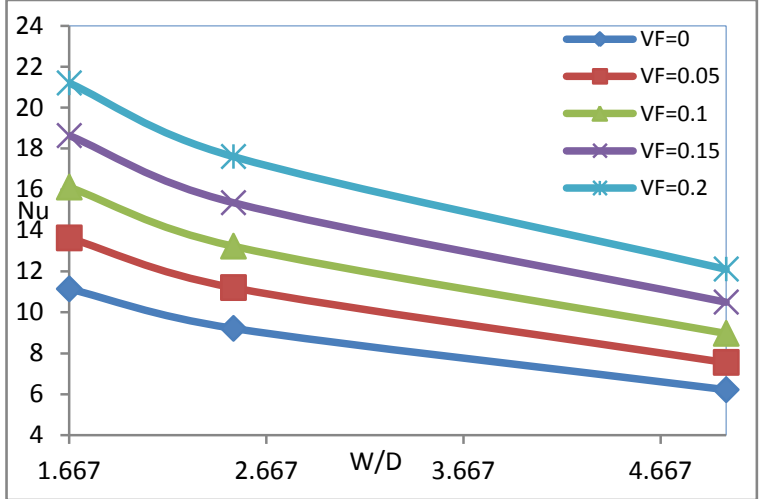

(c)

Fig. (10): Effect of enclosure width on Nusselt number for each volume fraction, (a) $\mathrm{Ra}=10^{4}$, (b) $\mathrm{Ra}=10^{5}$, (c) $\mathrm{Ra}=10^{6}$ and opening size $\mathrm{O} / \mathrm{W}=0.5$.

Figure (11) explain the influence of Rayleigh number on Nusselt number for opening size $\mathrm{O} / \mathrm{W}=0.5$. Figure 11 (a) mentioned the case at volume fraction $\varphi=0$. For the range of Rayleigh number $10^{4} \leq \mathrm{Ra} \leq 10^{5}$, a small increase in average $\mathrm{Nu}$ value is noticed. The average $\mathrm{Nu}$ enhancement has high value at the domain of Rayleigh number $10^{5}<\mathrm{Ra} \leq 10^{6}$. The average $\mathrm{Nu}$ varies inversely with enclosure width.

Figure 11(b, c) presents the impact of Rayleigh number on average $\mathrm{Nu}$ for volume fraction $\varphi=0.05$ and 0.1 . The average $\mathrm{Nu}$ increases slightly for the domain of Rayleigh number $10^{4} \leq \mathrm{Ra} \leq 10^{5}$. The enhancement in average $\mathrm{Nu}$ has remarkable value at the range of Rayleigh number $10^{5}<\mathrm{Ra} \leq 10^{6}$.

For the case of volume fraction $\varphi=0.15$ and 0.2 , figure $11(\mathrm{~d}, \mathrm{e})$ show inverse relationship between Nusselt number and enclosure width for each Rayleigh number. The average $\mathrm{Nu}$ increases significantly at the Rayleigh number range $10^{4} \leq \mathrm{Ra} \leq 10^{5}$. The enhancement in average $\mathrm{Nu}$ is more pronounced at the Rayleigh number range $10^{5}<\mathrm{Ra} \leq 10^{6}$. 


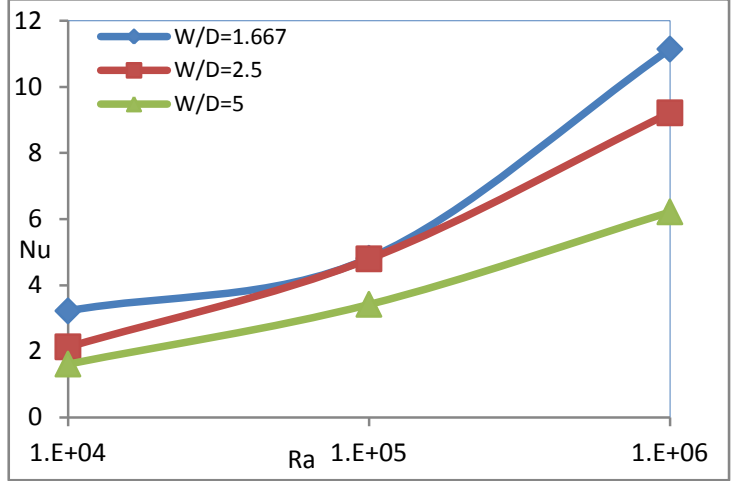

(a)

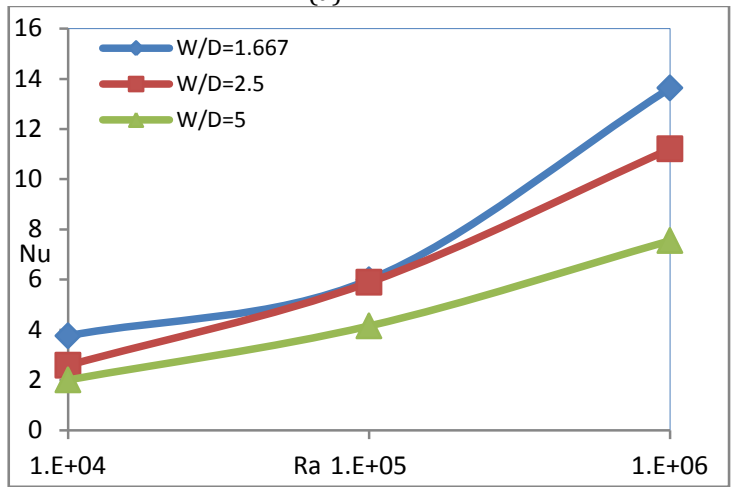

(b)

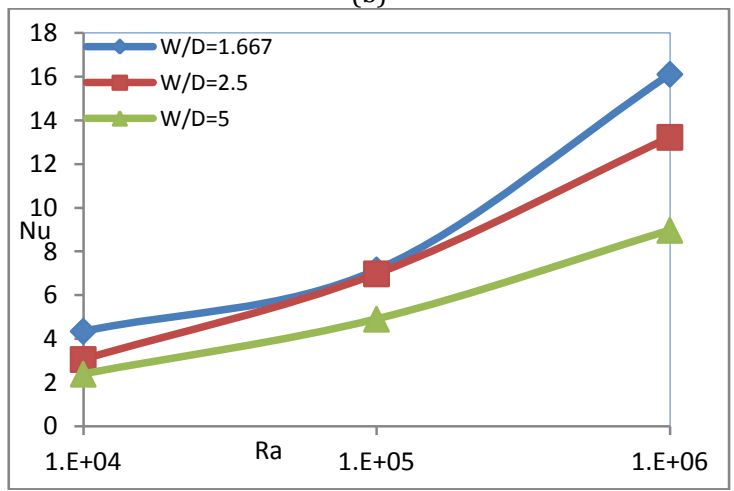

(c)

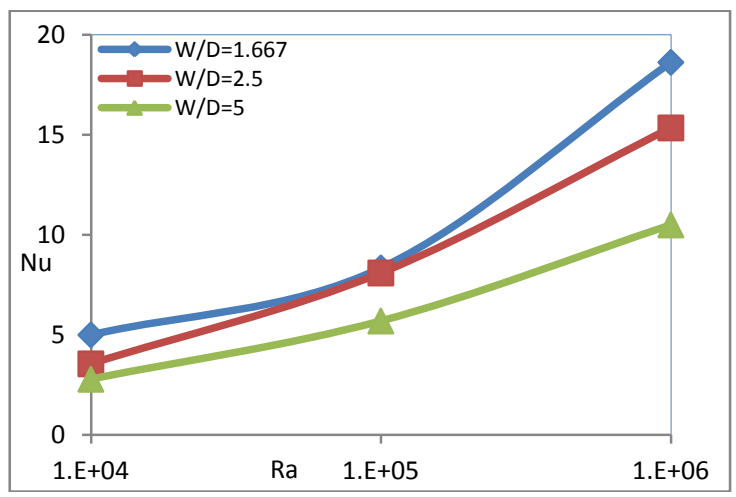

(d)

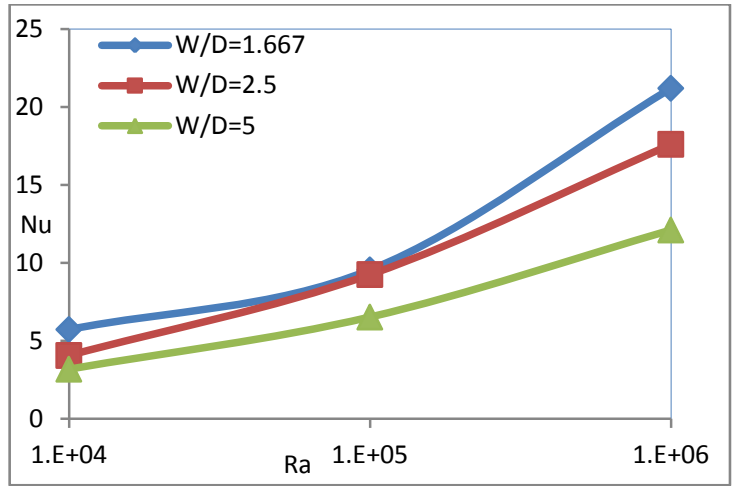

(e)

Fig. (11): Effect of Rayleigh number on Nusselt number for each enclosure width. (a) $\varphi=0$, (b) $\varphi=0.05$, (c) $\varphi=0.1$, (d) $\varphi=0.15$, (e) $\varphi=0.2$ and opening size $\mathrm{O} / \mathrm{W}=0.5$.

\section{CONCLOSIONS}

Natural convection heat transfer from horizontal circular cylinder in a vented enclosure containing nanofluid was investigated numerically for a wide range of Rayleigh number with taking the effect of enclosure width and opening size.

The main conclusions of this paper are:

1. The average $\mathrm{Nu}$ increase with increasing the Rayleigh number for each enclosure width, opening size and nanofluid volume fraction.

2. The average $\mathrm{Nu}$ increase with increasing opening size for each Rayleigh number, enclosure width and nanofluid volume fraction.

3. The average $\mathrm{Nu}$ decrease with increasing enclosure width for each Rayleigh number, opening size and nanofluid volume fraction.

4. The average Nusselt number increase with increasing nanofluid volume fraction for each Rayleigh number, opening size and enclosure width.

5. The strength of the flow increase with increasing the nanofluid volume fraction for each Rayleigh number, opening size and enclosure width.

6. The thickness of thermal boundary layer decrease with increasing the Rayleigh number for each opening size, enclosure width and nanofluid volume fraction

7. The maximum Nusselt number at opening size $\mathrm{O} / \mathrm{W}=1, \mathrm{~W} / \mathrm{D}=1.667, \varphi=0.2$ and $\mathrm{Ra}=10^{6}$ for all parameters.

8. The conduction heat transfer is the dominant mode for low Rayleigh numbers and convection 
heat transfer is the dominant mode for high Rayleigh numbers.

\section{REFERENCE}

-Shu C., Zhu Y. D., (2002), "Efficient computation of natural convection in a concentric annulus between an outer square cylinder and an inner circular cylinder", International journal for numerical method in fluids, 38:429-445.

-Ali O. M., Kahwaji G. Y., Hussien A. S., (2012), "Experimental investigation of natural convection heat transfer from square cross section cylinder in a vented enclosure", Applied mechanics and materials, 110116:4451-4464

-Abo-Nada E., Oztop H. F., (2009), "Effect of inclination angle on natural convection in enclosure filled with $\mathrm{Cu}$-water nanofluid", International journal of heat and fluid flow, 30(4):669-678.

-Fletcher C., A., J., (1988), "Computational Techniques for Fluid Dynamics 2", Springer - Verlag.

-Hakan F. Oztop, Eiyad Abu-Nada, (2008), "Numerical study of natural convection in partially heated rectangular enclosures filled with nanofluids," International Journal of Heat and Fluid Flow 29:1326-1336.

-Ali O. M., kahwaji G. Y., (2014), "Numerical investigation of natural convection heat transfer from circular cylinder inside an enclosure using different types of nanofluid", Journal impact factor, 5(5):214236.

-Salman A. M., (2011), "An investigation of natural convection heat transfer in a square enclosure filled with nanofluid", Eng. \& Technology, 29(12):2346-2363
-Saleh H., Roslan R., Hashim I., (2011), "Natural convection heat transfer in a nanofluid filled trapezoidal enclosure", International journal of heat and mass transfer, 54:194201.

-Brinkman H. C., (1952), "The viscosity of

-concentrated suspensions and solution", J. Chem. Phys., 20:571-581

-Ali O. M., (2007), "Experimental and Numerical Investigation of Natural Convection Heat Transfer from Different Cross Section Cylinders in a Vented Enclosure", Ph. D. Thesis, Thermal Power, Mechanical Engineering, University of Mosul.

-Ali O. M., Zaidky R. H. S., Saleem A. M., (2014), "Numerical investigation of natural convection heat transfer from circular cylinder inside an enclosure containing nanofluid", Journal impact factor, 5(12):6685.

-Pletcher R. H., Tannehill J. C., Anderson D. A., (2013), "computational fluid mechanics and heat transfer", Third edition by Taylor \& Francis Group, LLC.

-Thomas P. D., Middlecoff J. F., (1980), "Direct Control of the Grid Point Distribution in Meshes Generated by Elliptic Equations", AIAA Journal, 18(6): 652-656.

-Spalding D.B., (1972), "A Novel Finitedifference Formulation for Differential Expression Involving Both First and Second Derivatives", Int. J. Numer. Methods

-Eng., 4:551-559.

-Moukalled F., Acharya S., (1996), "Natural convection in the annulus between concentric horizontal circular and square cylinders", Journal of Thermophysics and Heat Transfer, 10(3):524 -531. 
Table (2): The three governing equations represented by interchanging the dependent variable $\phi$.

\begin{tabular}{|c|c|c|c|c|c|c|}
\hline$\phi$ & $a_{\phi}$ & $\mathrm{b}_{\phi}$ & \multicolumn{4}{|c|}{$d_{\phi}$} \\
\hline$\psi$ & 0 & 1 & \multicolumn{4}{|c|}{$\omega$} \\
\hline \multirow[t]{3}{*}{$\omega$} & 1 & $\operatorname{Pr}$ & \multirow{3}{*}{$\operatorname{RaPr}$} & & \multirow[b]{2}{*}{1} & \multirow{3}{*}{$\left(y_{\eta} \theta\right)_{\xi}-\left(y_{\xi} \theta\right)_{\eta}$} \\
\hline & & \multirow{2}{*}{$\left((1-\varphi)+\varphi \frac{\rho_{s}}{\rho_{f}}\right)$} & & $1 \quad \beta_{s}+$ & & \\
\hline & & & & $\frac{(1-\varphi)}{\varphi} \frac{\rho_{f}}{\rho_{s}}+1 \beta_{f}$ & $\frac{\varphi}{(1-\varphi)} \frac{\rho_{f}}{\rho_{s}}+1$ & \\
\hline $\mathrm{T}$ & 1 & & & & 0 & \\
\hline
\end{tabular}

Table (3): Comparisons of maximum stream function and Nusselt numbers

\begin{tabular}{|c|c|c|c|c|c|}
\hline \multirow[t]{2}{*}{ W/D } & \multirow[t]{2}{*}{$\mathbf{R a}$} & \multicolumn{2}{|c|}{$\psi_{\max }$} & \multicolumn{2}{|c|}{$\overline{N u}$} \\
\hline & & Present & $\begin{array}{c}\text { Moukalled and } \\
\text { Acharya [15] }\end{array}$ & Present & $\begin{array}{c}\text { Moukalled and } \\
\text { Acharya [15] }\end{array}$ \\
\hline 5.0 & $10^{4}$ & 1.7427 & 1.73 & 2.45 & 2.071 \\
\hline 2.5 & & 0.9584 & 1.02 & 3.182 & 3.331 \\
\hline 1.67 & & 0.4273 & 0.5 & 5.22 & 5.826 \\
\hline 5.0 & $10^{5}$ & 10.10 & 10.15 & 3.889 & 3.825 \\
\hline 2.5 & & 8.176 & 8.38 & 4.93 & 5.08 \\
\hline 1.67 & & 4.8644 & 5.10 & 6.23 & 6.212 \\
\hline
\end{tabular}



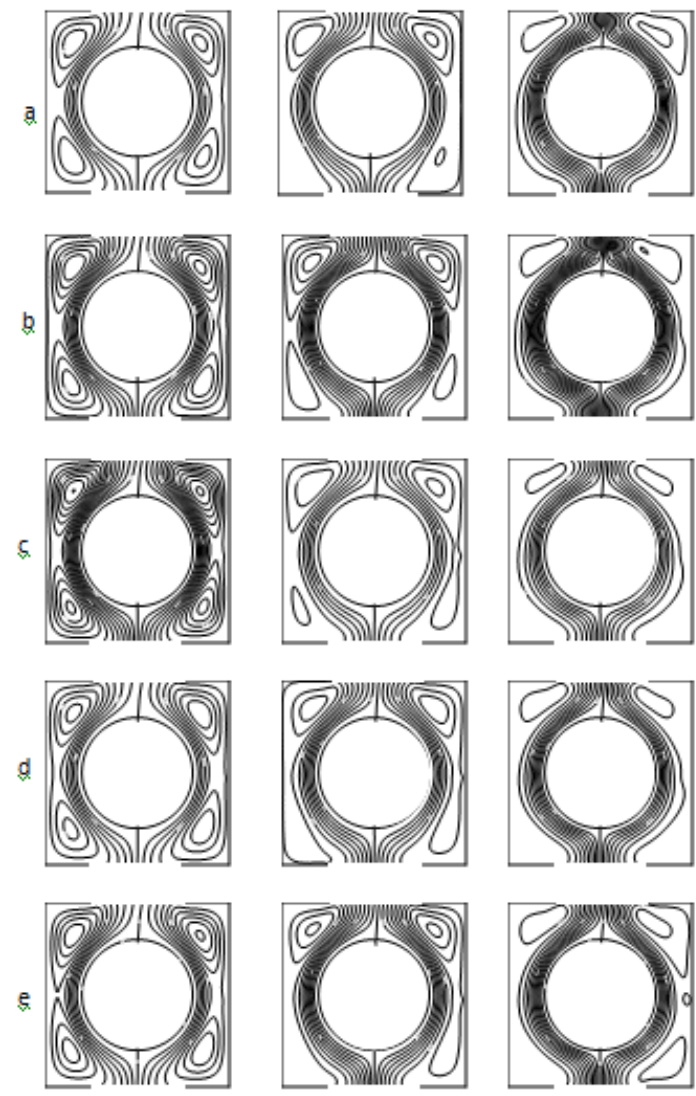

$\mathrm{Ra}=10^{4}$

$\mathrm{Ra}=10^{5}$
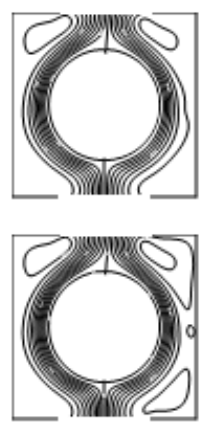

$\mathrm{Ra}=10^{5}$

Figure (2) effect of volume fraction on the streamline at $\mathrm{W} / \mathrm{D}=1.667, \mathrm{O} / \mathrm{W}=0.5$ and different Rayleigh number (a) $\varphi=0$, (b) $\varphi=0.05$, (c) $\varphi=0.1$, (d) $\varphi=0.15$, (e) $\varphi=0.2$.
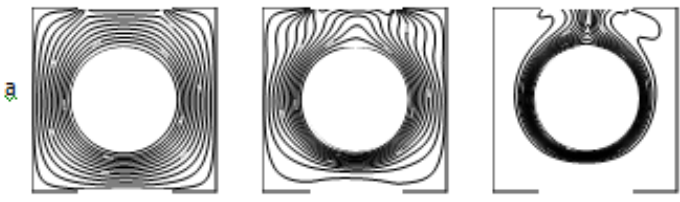

b
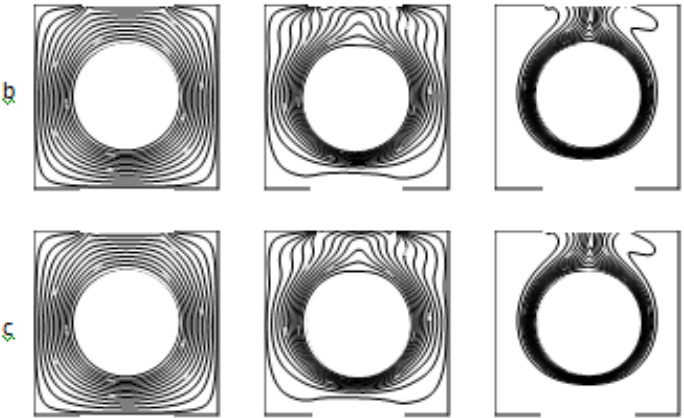

d
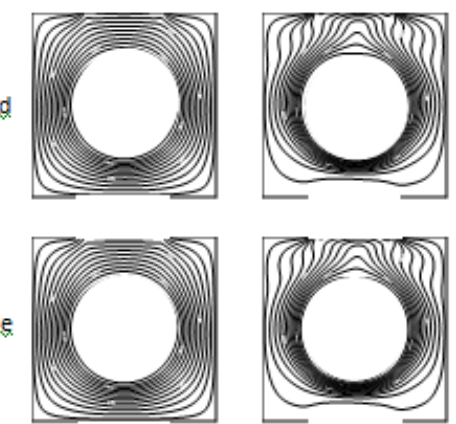

$\mathrm{Ra}=10^{4}$

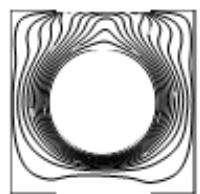

$\mathrm{Ra}=10^{3}$
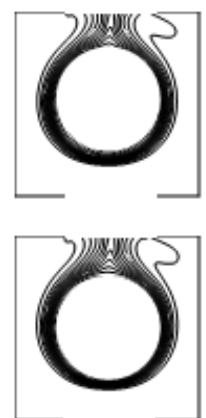

$\mathrm{Ra}=10^{5}$

Figure (3) effect of volume fraction on the isotherm at $W / D=1.667$, $\mathrm{O} / \mathrm{W}=0.5$ and different Rayleigh number (a) $\varphi=0$, (b) $\varphi=0.05$, (c) $\varphi=0.1$, (d) $\varphi=0.15$, (e) $\varphi=0.2$. 

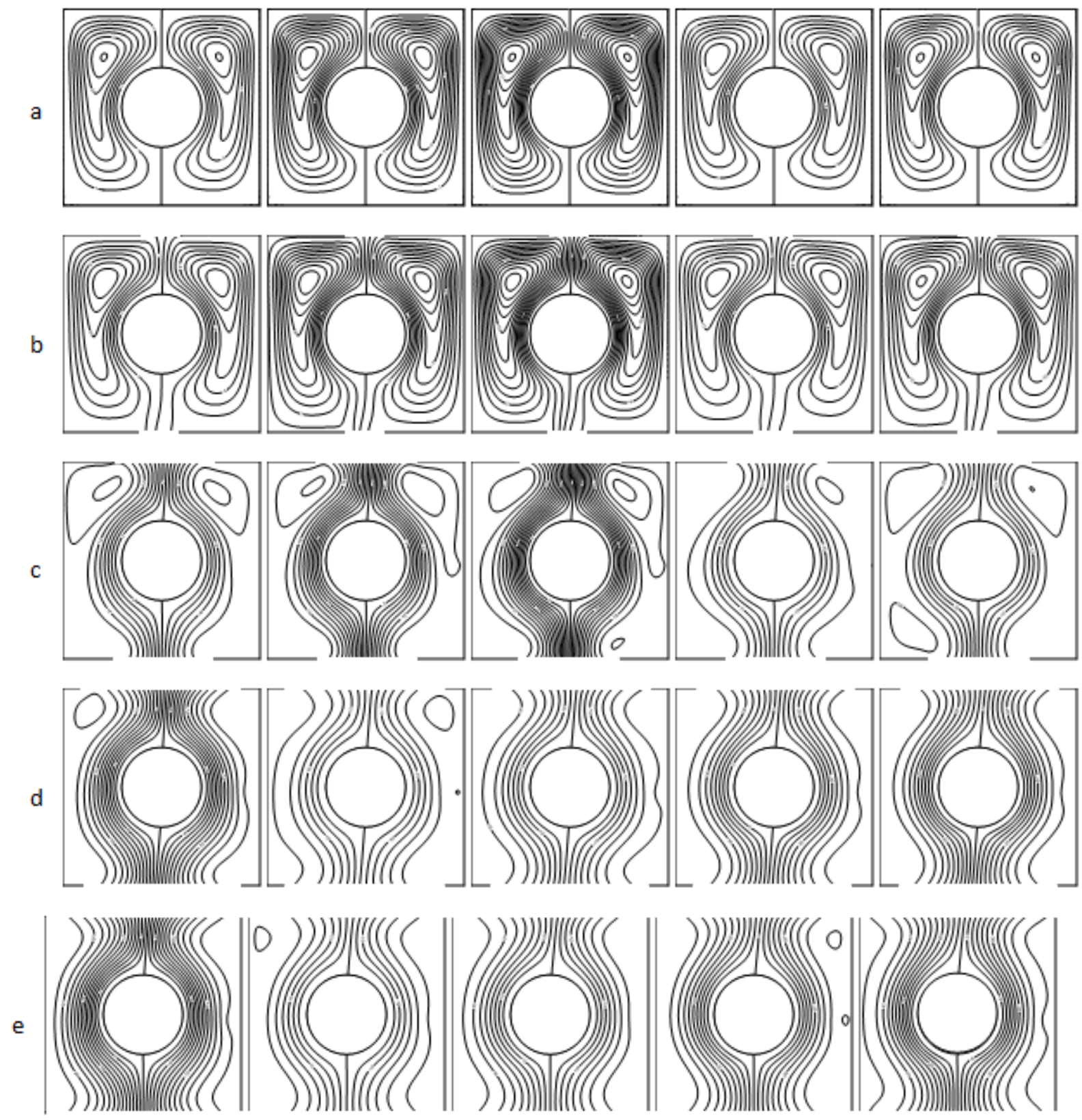

$$
\varphi=0
$$$$
\varphi=0.05
$$$$
\varphi=0.1
$$$$
\varphi=0.15
$$$$
\varphi=0.2
$$

Fig. (4): effect of opening size on the streamline for $\mathrm{W} / \mathrm{D}=2.5, \mathrm{Ra}=10^{5}$ and Different volume fraction of nanofluid a) $\mathrm{O} / \mathrm{W}=0$, (b) $\mathrm{O} / \mathrm{W}=0.2$, (c) $\mathrm{O} / \mathrm{W}=0.5$, (d) $\mathrm{O} / \mathrm{W}=0.8$, (e) $\mathrm{O} / \mathrm{W}=1$. 
a
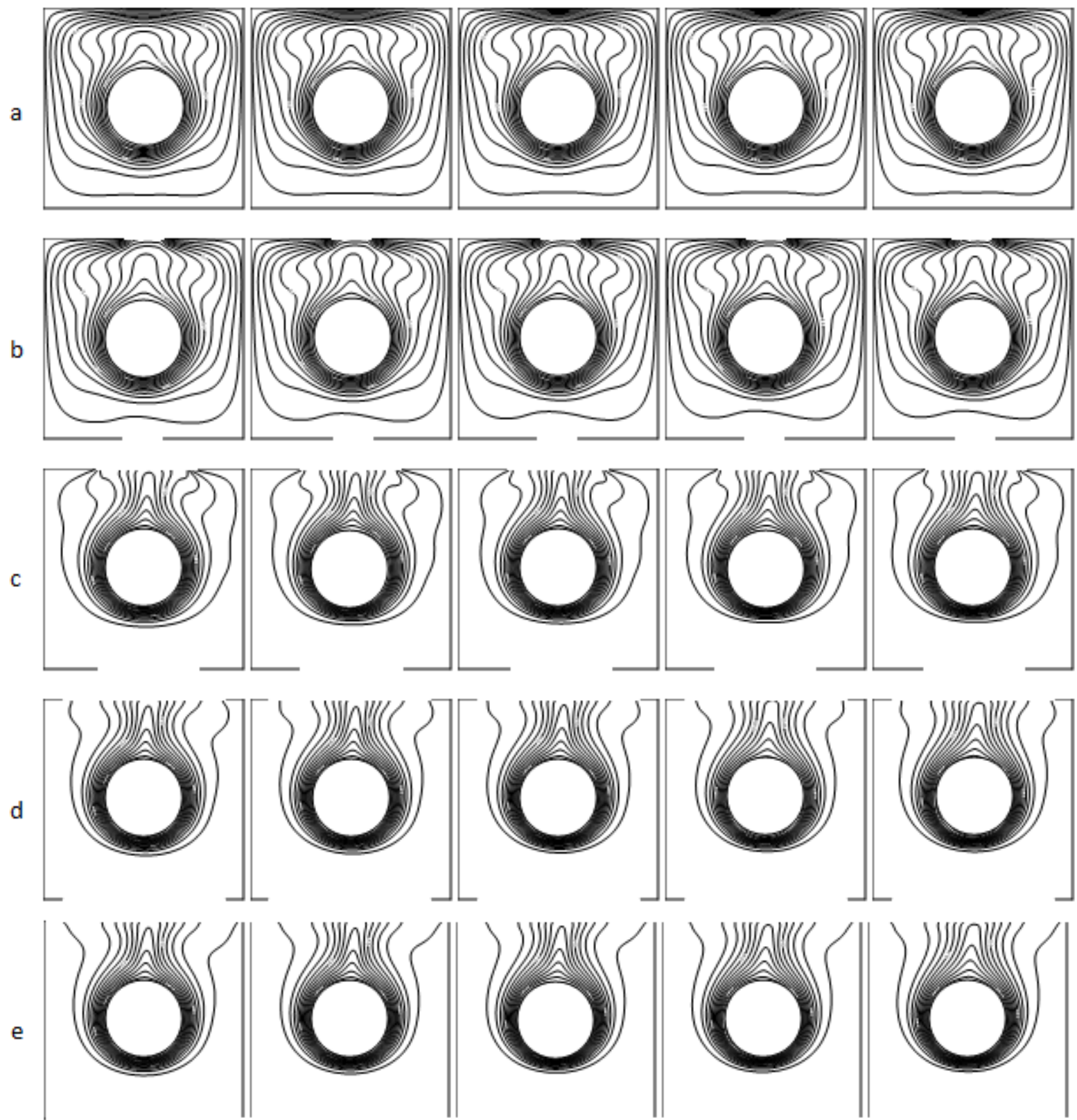

$\varphi=0$

$\varphi=0.05$

$\varphi=0.1$

$\varphi=0.15$

$\varphi=0.2$

Figure (5) effect of opening size on the isotherm for $\mathrm{W} / \mathrm{D}=2.5$ and $\mathrm{Ra}=10^{5}$ and different volume fraction of nanofluid (a) $\mathrm{O} / \mathrm{W}=0$, (b) $\mathrm{O} / \mathrm{W}=0.2$, (c) $\mathrm{O} / \mathrm{W}=0.5$, (d) $\mathrm{O} / \mathrm{W}=0.8,(\mathrm{e}) \mathrm{O} / \mathrm{W}=1$. 

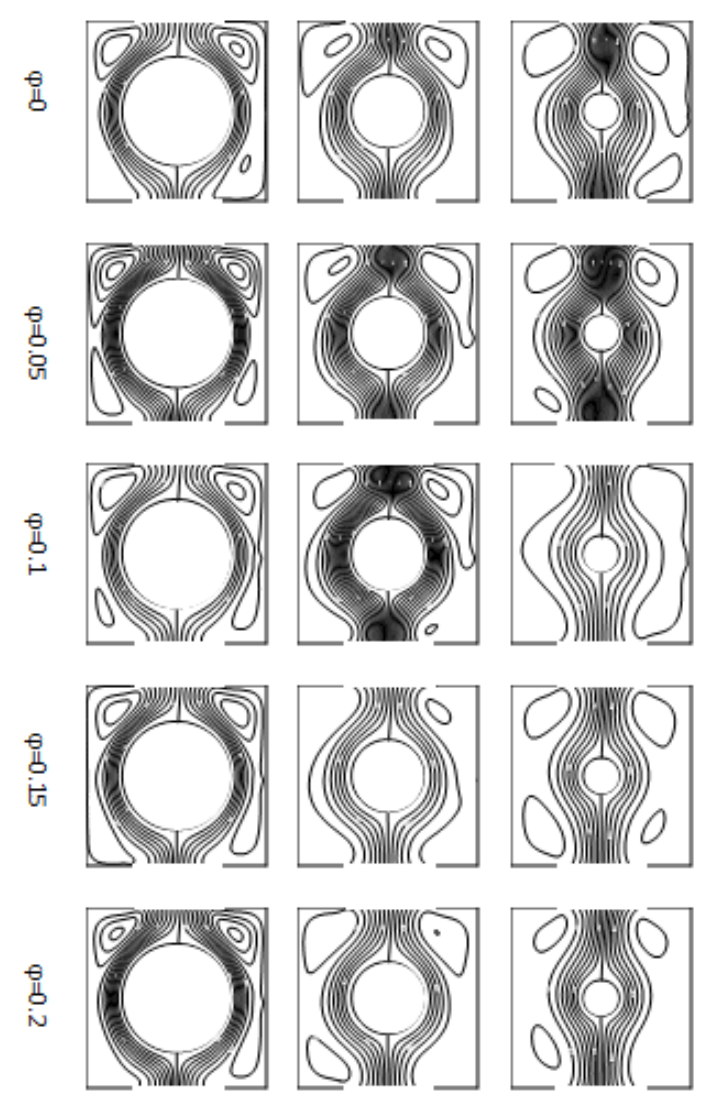

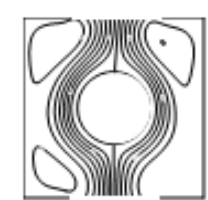

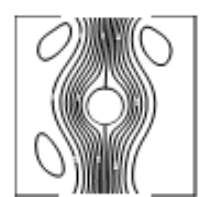

c

Figure (6) effect of enclosure widths on the streamline for $\varphi=0$, $0.05,0.1,0.15$ and $0.2, \mathrm{Ra}=10^{5}$ and $\mathrm{O} / \mathrm{W}=0.5$ (a) $\mathrm{W} / \mathrm{D}=1.667$, (b) $\mathrm{W} / \mathrm{D}=2.5$, (c) $\mathrm{W} / \mathrm{D}=5$.
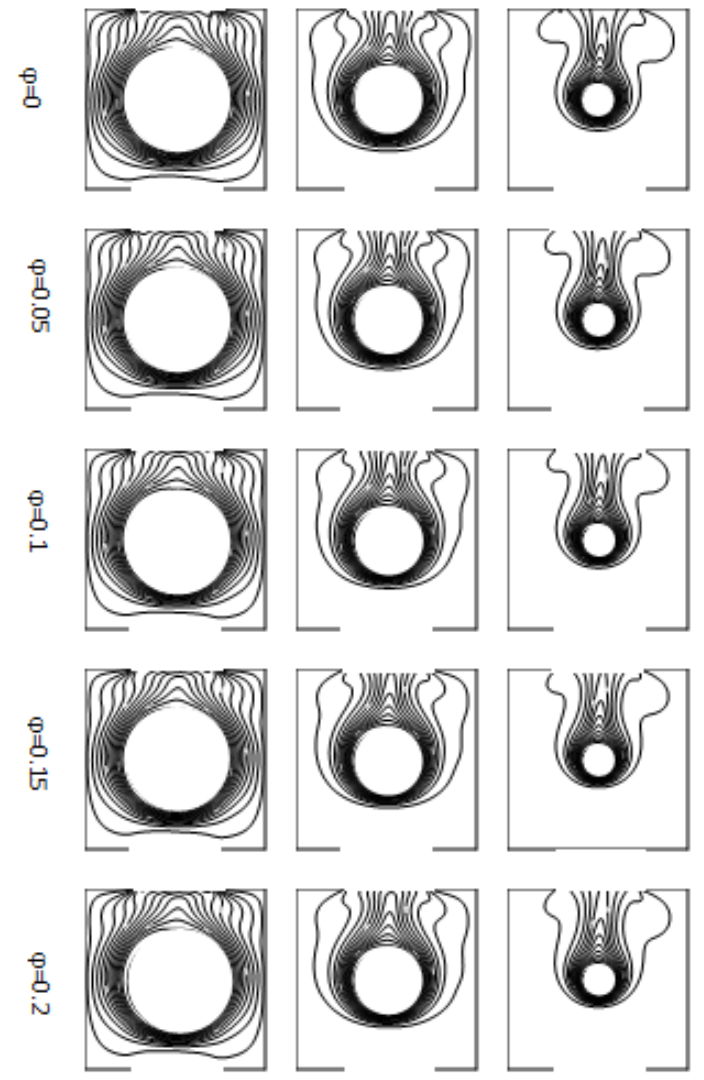

a

b

c

Figure (7) effect of enclosure widths on the is otherm for $\varphi=0,0.05$, $0.1,0.15$ and $0.2, R_{a}=10^{5}$ and $O / W=0.5$ (a) $W / D=1.667$, (b) $\mathrm{W} / \mathrm{D}=2.5$, (c) $\mathrm{W} / \mathrm{D}=5$. 
در اسة عددية لانتقال الحرارة بالحمل الطبيعي من اسطوانة افقية موضوعة في تجويف مملوء بمائع نانوي من

الخلاصة

يتضمن العمل الحالي دراسة عددية لانتقال الحرارة بالحمل الطبيعي من اسطوانة دائرية أفقية في

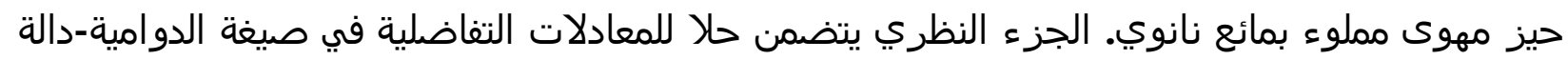

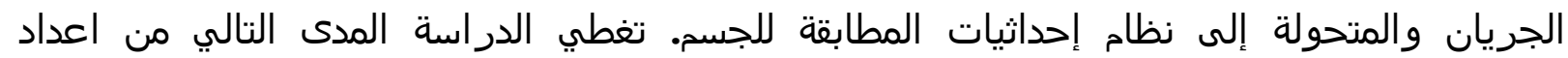
رايلي(15a

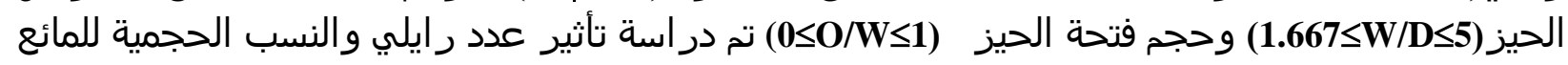

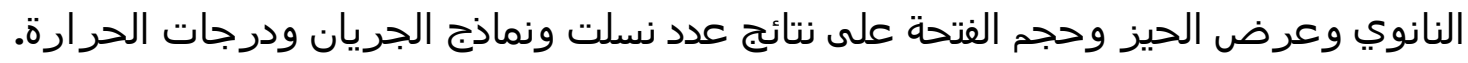

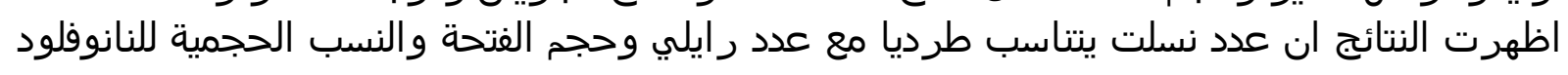

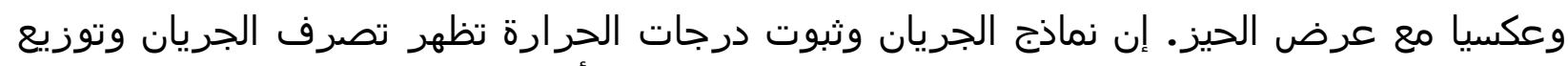

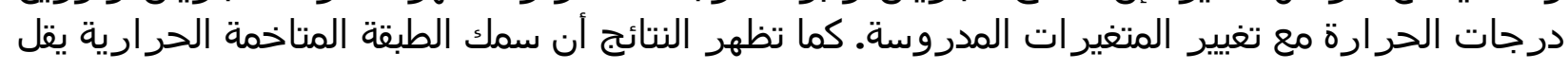
مع زيادة عدد رايلي لكل عرض الع حير المنغيرات المدروسم فتحة ونسبه حجمية للمائع النانوي. 